\title{
우리말 신경학용어
}

\section{하상원 김상범 ${ }^{a}$ 김병건 ${ }^{b}$ 조상걸 ${ }^{c}$ 송홍기 ${ }^{d}$}

한국보훈복지의료공단 중앙보훈병원 신경과, 경희대학교 의과대학 강동경희대병원 신경과

을지대학교 의과대학 노원을지대학교병원 신경과 ${ }^{\mathrm{b}}$ 고려대학교 의과대학 구로병원 응급의학과, 한림대학교 의과대학 강동성심병원 신경과

\section{Korean Neurological Terminology}

Sang-Won Ha, MD, PhD, Sang-Beom Kim, MD, PhD ${ }^{a}$, Byung-Kun Kim, MD, PhD ${ }^{b}$, Sang-Gull Cho, $\mathrm{MD}^{\mathrm{c}}$, Hong-ki Song, MD, $\mathrm{PhD}^{\mathrm{d}}$

Department of Neurology, Veterans Health Service Medical Center, Seoul, Korea

Department of Neurology, Kyung Hee University Hospital at Gangdong, School of Medicine, Kyung Hee University, Seoul, Korea

Department of Neurology, Nowon Eulji Medical Center, Eulji University, Eulji University School of Medicine, Seoul, Korea $^{b}$

Department of Emergency Medicine, Korea University Guro Hospital, Korea University College of Medicine, Seoul, Korea $^{c}$

Departments of Neurology, Kangdong Sacred Heart Hospital, Hallym University College of Medicine, Seoul, Korea ${ }^{d}$

J Korean Neurol Assoc 38(3):175-182, 2020 https://doi.org/10.17340/jkna.2020.3.2

J Korean Neurol Assoc 38(4):384, 2020

대한신경과학회지에 게재된 위 논문에서 교신저자의 정보에 오류가 있었습니다.

Address for correspondence: Hong-ki Song, $\mathrm{MD}, \mathrm{PhD}$

Departments of Neurology, Kangdong Sacred Heart Hospital, Hallym University College of Medicine,

150 Seongan-ro, Gangdong-gu, Seoul 05355, Korea

Tel: +82-2-2224-2206 Fax: +82-2-2224-2339

E-mail: hksong0@hanmail.net 